\section{Conversion from migraine without aura to typical aura without headache after irbesartan}

\section{Pinessi • M. Ferrero \\ S. Gentile • I. Rainero \\ Published online: 8 April 2005}

Sir,

There is a long and still open controversy over whether migraine with aura (MA) and migraine without aura (MO) are separate entities or subtypes of the same disorder [1]. We report the case of a patient suffering from MO that, after starting an antihypertensive therapy with irbesartan, experienced a significant reduction of MO attacks but developed typical aura without headache.

A 51-year-old Caucasian woman was admitted in February 2003 as an out-patient in our Headache Center for episodes of scintillating scotoma affecting right visual field. Since age 27 , the patient had complained of headache attacks fulfilling the ICHDII criteria [2] for MO. In December
2002, the patient developed mild arterial hypertension and her family physician prescribed irbesartan 150 $\mathrm{mg}$ daily. In the following months, the patient perceived a significant reduction of headache attacks. However, in January 2003 the patient developed an attack of migraine aura without headache. She reported symptoms of a scintillating scotoma, gradually expanding across the right visual field and lasting for approximately $30 \mathrm{~min}$. The aura was not followed by headache. The patient had seven additional attacks in a two-year period, with the same clinical features. All the attacks fulfilled the ICHD-II criteria for 'Typical aura without headache' (code 1.2.3). Magnetic resonance imaging scan of the brain did not reveal any abnormalities. Extensive blood testing was normal. Factor V Leiden (R506Q) and prothrombin (G20210A) gene mutations were absent.

This is the first case, to our knowledge, describing the conversion of MO into typical aura without headache after antihypertensive therapy. Mammalian brain harbours a renin-angiotensin system [3] and angiotensin receptors $\left(\mathrm{AT}_{1}, \mathrm{AT}_{2}\right.$ and $\mathrm{AT}_{4}$ ) are plentiful in human brain. Our case report suggests a possible role for angiotensin receptors in the pathophysiology of migraine aura. Additional clinical and experimental studies may be helpful to clarify this issue.

\section{References}

1. Wilkinson M, Blau JN (1983) Are classical and common migraine different entities? Headache 25:211-212

2. Headache Classification Subcommittee of the International Headache Society (2004) The International Classification of Headache Disorders, 2nd edn. Cephalalgia 24[Suppl 1]:1-151

3. McKinley MJ, Albiston AL, Allen AM, Mathai ML, May CN, McAllen RM, Oldfield BJ, Mendelsohn FA, Chai SY (2003) The brain reninangiotensin system: location and physiological roles. Int J Biochem Cell Biol 35:901-918

L. Pinessi • M. Ferrero $\bullet$ S. Gentile I. Rainero (西)

Neurology III, Headache Center, Department of Neuroscience, University of Turin,

Via Cherasco 15, I-10126 Turin, Italy e-mail: irainero@molinette.piemonte.it Tel.: +39-011-6638510

Fax: +39-011-6638510 